\title{
Erratum to: Non-medical Prescribingby Pharmacists
}

\author{
Graham Brack
}

\section{Erratum to:}

Chapter 5 in: Penelope Mary Franklin (ed.), Non-medical Prescribing in the United Kingdom https://doi.org/10.1007/978-3-319-53324-7_5

The authors who were listed under the heading DHSSPNI were contributors to chapter 4 "Non-medical Prescribing in Northern Ireland" and have no association with Graham Brack who is the author for chapter 5. These errors were on pages 109 and 110. Chapter 5 is updated.

The updated online version of the book can be found at https://doi.org/10.1007/978-3-319-53324-7_5 